\title{
REFLEXÕES SOBRE O PESQUISAR PARA EDUCAR
}

\author{
Marilene Schmarczek*
}

Inicialmente agradeço o convite à Comissão que programou esta mesa-redonda, o que muito me honra.

Chamo a atenção que um dos limites desta minha fala é a ausência de pesquisa sobre o que exporei. Tento aqui ensaiar algumas reflexóes e aponto algumas questőes que me preocupam, redigidas com antecedência, de modo a facilitar a tradução. Lastimo que a distância não me tenha possibilitacio encontrar as colegas, participantes dessa mesa, para pontuarmos nossas apresentaçōes.

O estudar/" pesquisar" em livros, revistas, textos, relatos, reflexões, teorias tem sido uma ação utilizada no processo educacional, como meio de resolver questões, dúvidas, obter ou aprofundar conhecimentos. $O$ mesmo ocorre quando se buscam referenciais a trabalhos cientificos ou práticas de campo.

Paralelamente, o conhecimento é repassado no trabalhar com o experimentado - vendo-o, ouvindo-o ou com ele discutindo.

No exercício profissional empregam-se esses meios na busca de conhecimentos e fundamentaçáo à prática de enfermagem, seja no âmbito da docência, da pesquisa, da assistência, da administração ou das assessorias.

A fundamentação de uma prática, quando empregada, tende a explicar o que se faz. O que pode ter origem no conhecimento acumulado pela cultura popular ou pela cultura científica.

Nem sempre a fundamentação e, em conseqüência, a prática são resultantes de investigação. Existem práticas executadas com base em ritos, mitos, crenças. Nesses casos, o executor nelas crê ou a elas se submete por ignorância, opção ou coação.

Outras práticas são executadas com base em referênciais oriundos de autores que são ou não pesquisadores que divulgam os resultados de seus estudos ou experiências.

Nem sempre, também, aquele que aplica esses resultados examina-os em seu cotidiano ou investiga-os, antes de executá-los em sua realidade.

A pesquisa, enquanto proposta educacional, assume a representação de meio para educar e de fim, enquanto resultado do que se pesquisa como processo educacional de como ensinar a aprender e como aprender a ensinar, de como ensinar aprendendo, de como aprender ensinando e processando ensino/aprendizagem para apreender o conhecimento e executá-lo enquanto conhecimento aprendido.

- Enfermeira. Professor Titular Inativa da UFRS. Doutora em Educação. 
Essa representação de conhecimentos, até então não aprendidos, requer, para executá-la, uma nova abordagem que permita processar esse conhecimento da pesquisa à educação.

Portanto, o pesquisar integrado ao educar é um processo que requer novas abordagens, novas aprendizagens, especialmente a leitura crítica do que se produziu, do que está dado, instituído, aprovado.

A leitura, também, do não escrito, mas ocorrido ou que ocorre, ou das conseqüências do que existe e suas relaçóes. Envolve a leitura da realidade, o questionamento sobre a realidade e o conhecimento existente sobre essa realidade.

No pesquisar para educar, assim entendido, necessita-se aprender a pesquisar. Necessita-se a auto-educação para pesquisar e para educar.

Essa combinação ou cadeia requer o aprofundamento e desenvolvimento de práticas, entre outras, aparentemente "desnecessárias" ao pesquisador/educador, ou seja, o reaprender a ver, ouvir, sentir, observar, olhar, tocar, trocar, ler, entrevistar, examinar, colher dados, registrar, interpretar, avaliar, auto-avaliar-se, escrever, descrever, reescrever, associar, afirmar, contrariar, calcular, analisar, refletir, concluir, sintetizar, apresentar, formular hipoteses, discutir fatos e fenómenos buscando entendé-los em sua magnitude, contexto, especificidade, totalidade. Captar fatos e fenomenos, seus determinantes e suas implicações. Como esses se modificam, interferem, obscurecem, mascaram, perpetuam, mistificam verdades. Aprender a nova prática sem perder ou negar aquilo que se sabe ou praticou e que permitiu ver e andar para o transformar-se e transformado.

Outra questão que emerge deste entendimento, sobretudo no que diz respeito à leitura da realidade, é o compromisso com o outro e consigo - enquanto cidadãos -, com a sociedade, com as condições de trabalho, com o conhecimento, com a ética e com a ecologia; na promoção dos direitos e no exercício dos deveres de igualdade, em especial à saúde.

O processo de pesquisar/educar passa pelo questionamento do pesquisar/educar o quê? Para quem? Como? Quando? Com que meios e fins? Em que condições? Remete ao pesquisar/educar/pesquisar.

$O$ pesquisar para educar pode manter a relação do que pesquisa para educar, com aquele que se educa e é educado por alguem, que pesquisou para educá-lo. Nessa visão mantém-se a distância entre os seres e se reduz o espaço para o conhecimento que se desenvolve face a enfrentamentos, interações horizontais. Criam-se distanciamentos, enquanto focos de comunicação, instâncias e relaçóes de poder, focos do que se realiza no cotidiano e, em conseqüência, o tempo em que se sistematizam resultados e descobertas.

O pesquisar/educar/pesquisar aproxima espaços, conteúdos e realidades que devem ser aproveitados, pois interagem entre si sendo carregados de dados e imprescindíveis para a totalidade do conhecimento. Seus sujeitos estão envolvidos, seja no processo de trabalho, seja no processo de aprender, seja no processo de promover, garaniir, tratar ou recuperar sua saúde.

Nesse entendimento, pesquisa/educar/pesquisar constitui-se numa rede que requer a integração de todos os sujeitos - atores/autores com seus conhecimentos, caracteristicas, ambientes ou situaçōes, com os quais estão envolvidos. Num processo de captar essas relações de forma ordenada e desordenada, sistematizando-as e lendo-as sucessivamente. Captando fatores, fenômenos, situações 
que com elas interagem. Tomando consciência do que, como, quando, por que, com que fim ocorrem.

O pesquisar para educar revela que a enfermagem é uma profissão social que aplica o conhecimento das diferentes ciências no exercício de sua prática, obtendo resultados.

No cotidiano, essa prática tem sofrido a ausência de registro e espaço para estudar e refletir sobre o que se aplica. O que resulta desta aplicação? Como a clientela percebe toda essa prática?

Qual a representaçăo e o significado da enfermagem para a população, para outros profissionais, para a própria enfermagem? Como a enfermagem se insere - e está inserida - dentro da ética, da ciência, da tecnologia e da política:a de saúde? Qual o significado dos corpos com os quais lidamos?

Estas questőes nem sempre são aprofundadas na sala de aula, nos laboratórios ou nos campos de estágio.

$\mathrm{Na}$ organização do trabalho em saúde o espaço para pesquisar, o que se realiza em enfermagem, é reduzido ou inexistente. Isso não contribui para o desenvolvimento dessa prática e do seu significado para a melhoria das condições de saúde da população, o que não difere de outras profissões.

O número de enfermeiros que exercem atividades no setor saúde é pequeno se comparado com os componentes da equipe de enfermagem e médicos, sobretudo se relacionarmos esse número com a população. $O$ que já denota ausência de ocupação do espaço e contato abrangente com a mesma população.

A tradição de pesquisa no país é reduzida a alguns setores e até regióes. Os investimentos em ciência e tecnologia são escassos, o que tem mobilizado protestos desse setor e das universidades, sobretudo as públicas.

Essa tradição reduz a existência de meios, a garantia da permanência de recursos para a execução de projetos e de pessoal qualificado. Isso diminui, como conseqüência, o potencial de envolvimento tanto humano como material, bem como o retorno para o próprio setor, o que é considerado investimento a fundo perdido.

Por outro lado, isso gera uma inércia quanto a aplicações de recursos locais e imediatos, relacionados às práticas de profissionais ou serviços, seja em saúde ou educação.

No caso da saúde, a ausência de registros é um indicador do descompromisso com o significado do dado, como fonte de pesquisa e com a clientela.

Da mesma forma os profissionais não lutam por esse espaço, como condição mínima para desenvolver sua prática e ironizam os que assim a vêem. Muitas vezes, esses profissionais também não lutam por melhores condições de trabalho ou pela melhoria da qualidade do trabalho que realizam e, conseqüentemente, pela melhoria das condições de saúde e vida da população. Talvez, até por investirem no campo privado na tentativa de obterem a qualidade de assistência que buscam para si, com uma certeza que não farão uso, nem se submeterão à prática que executam.

Por sua vez, a tecnologia empregada para facilitar o andamento do trabalho ou a rapidez de sua resolutividade, muitas vezes esbarra no sucateamento. Seja pela rápida transformação tecnologica, que sofistica mecanismos e insumos. Seja na ausência de mão-de-obra qualificada, para manter ou recuperar o funcionamento de suas engrenagens. 
Outro fator limitante da pesquisa e, conseqüentemente, do conhecimento, é a ausência de valorização e aproveitamento de recursos humanos qualificados ou qualificáveis que são submetidos a interesses pouco convincentes ou interesses ideologicos. Na mesma direção, não existe, na maioria das instituições, relação entre cargos, qualificações e salários.

Todos esses aspectos têm implicações educacionais e científicas. Educacionais por não valorizarem a educação/qualificação. Científicas porque tanto faz produzir ciência, pois o sistema de saúde investe na quantidade dos procedimentos realizados e não na qualidade ou resolutividade que converge para a saúde da população, da mesma forma que se importam tecnologias e terapêuticas.

O profissional, o pesquisador, o educador diante da clientela, dos sujeitos de pesquisa, dos educandos, expressa o que esses experimentam, enquanto eles estão ali, com suas vidas, experiências, dificuldades e caminhos de solução que possuem e vêem o falar de seus interlocutores ou esses as contam no prisma de suas próprías sensações, sem sequer escutá-los. Ou, em trabalhos científicos se apropriam dessas experiências para sua própria produção.

Essa cena é comum quando se aplica o processo avaliativo. Seja no plano da produção científica, seja no plano educacional, sem citar os demais. Produzem-se e avaliam-se trabalhos mas não se assume o cotidiano daquela produção. Avaliam-se educandos mas não se acompanha a trajetória de seu processo de aprender e do como foram ensinados. Cabe destacar que exceções existem, mas em geral não interessam. No entanto, são pontos relevantes para qualquer investigação visivelmente negligenciados na prática.

Outra reflexão que me parece oportuna é a da necessidade de pesquisa onde vê-se proliferar pesquisadores não educados para pesquisar, assim como educadores não educados para a pesquisa. Se esses assumissem seu próprio patamar, o de não estar preparados e daí assumissem o pesquisar-educar, teríamos um salto de qualidade a partir de uma noção de realidade. No entanto, proliferam cursos que exigem produção final de "trabalhos científicos", montam-se bancas examinadoras com nomes qualificados ou não. Submete-se os candidatos a esse ritual, quando tantas vezes essas instituições não têm recursos humanos qualificados em seus quadros permanentes, nem para orientá-los, mas que os avaliam. Os cidadãos avaliados dentro deste quadro real e funesto recebem seu conceito e se rotulam ou não, dependendo dos resultados, com a titulação permanente. Solitários, provavelmente não serão promovidos no campo em que trabalham. Isso também ocorre no conjunto das disciplinas que constituem os cursos, onde o pesquisar para ensinar aparece como lacuna.

Nesse mesmo prisma criam-se, nas instituições que executam a saúde, orgãos formadores, na proposta que as instituições educacionais não preparam para a realidade.

Os cidadãos e os profissionais, igualmente cidadãos, não questionam essas práticas como desvios de atribuições e verbas. Sejam, de um lado, dos investimentos e dos.compromissos que a educação e a pesquisa devem ter para com a sociedade, e, de outro, qual o compromisso dos serviços enquanto executores da política de saúde.

Refletindo sobre essa questão, se percebe que a realidade de saúde é determinada pelas condições de vida e acesso do brasileiro a seus direitos. Por sua vez, os serviços náo proporcionam, na sua maioria, condições de trabalho a seus 
profissionais e encaminhamento à solução de problemas de saúde a que a população tem direito. Nessa escassez ou falta de compromissos o conhecimento que possa transformar a realidade não é buscado.

Por essa cadeia passam os profissionais em formação com seus programas de curso. Esses, ou reproduzem o que se realiza na prática desses serviços, ou produzem as práticas que lhes interessam. Poucas vezes, serviços, população e instituições formadoras se associam na promoção do conhecimento aplicável/adaptável à realidade local, às práticas que viabilizam o conhecimento que é próprio dessa realidade, ao conhecimento que viabiliza essas práticas e suas transformações.

Toda essa reflexão pode parecer estranha ao tema, mas dele é integrante como parte do contexto. Assim, retomo a temática da enfermagem, que, por sua natureza e prática, requer a aplicação integrada de diferentes ciencias c de diferentes abordagens metodologicas de pesquisa.

O trato com o biologico requer metodologias que divergem das metodologias das ciências humanas que têm igual significado na enfermagem, sendo a combinação de ambas imprescindível.

O enfermeiro, enquanto educador, e o educando estabelecem uma relação que deve ser fundamentada e pesquisada na realidade, enquanto prática das ciências humanas, se focalizado o processo educacional. Essa ciência também fundamenta as relações de trabalho - seja com grupos, equipes - permitindo a pesquisa com a leitura do que, como, quando, com quem ocorre.

A ciência biológica articulada às ciências exatas favorece o controle dos processos invasivos que possam ocorrer tanto com a cliertela, como com a equipe, com o meio em seu equilíbrio ecológico. Um exemplo corresponde a proteção contra qualquer método que possa proporcionar risco de exposição. Cabe destacar que questões éticas, econômicas e políticas podem implicar no sentido de expor ao risco e, como tais, devem ser pesquisadas e anunciadas. Isso exemplifica a associação dos diferentes setores do conhecimento.

A associação de metodologias apropriadas às diferentes ciencias pode ser articulada para responder questões, como por exemplo: como é mantida, tratada e recuperada a saúde dos cidadãos? Como esses estão inseridos na sociedade? Como se processa a decisão de doar órgãos?

Cabe destacar que esses conhecimentos, para serem aprendidos, passam necessariamente pela aprendizagem que requer a passagem pelo processo educacional, pela pesquisa do educacional, no sentido de apreender o conhecimento. Em contrapartida, esse processo educacional deve estar associado ao conhecimento específico de aprendizagem e de obtenção e pequisa desse conhecimento. Isso se dá tanto na educação de enfermagem, como no processo educacional da clientela ou da equipe, consideradas as características, as relações, conforme apontado anteriormente.

$\mathrm{Na}$ área sindical ou administrativa, um exemplo de articulação diz respeito às condições de trabalho em enfermagem que devem ser pesquisadas e, como conseqüência, resultará em processos educativos ou jurídicos que desencadeiem entre trabalhadores e empregadores mudarças conseqüentes, tanto biológicas como sociais, propiciando melhorias nas condições de trabalho, no trabalho, na produção e nas condições de saúde e vida. 
Por último, quero aproximar o processo de pesquisar/educar em mais dois pontos.

O primeiro é o significado e contribuição desta Escola para com o tema. Parece-me que esta tem procurado, em meio a todo o conjunto contraditório em que vivemos, impulsionar a enfermagem enquanto profissão e campo do conhecimento.

Cabe lembrar que se Horta hoje é estigmatizada por insistir no processo de enfermagem e o referencial das necessidades humanas básicas a ele aplicado, 0 é por não ter se omitido. Sua passagem pela enfermagem é inequívoca. Na busca de sistematização de nossos conhecimentos. Obviamente, não de uma enfermagem enquanto ciência idenpendente, mas pelo agir com consciência e com ciência. Se criticada, é pelo que construiu, pelo que mobilizou perseguindo a busca da verdade e conhecimento. Nessa caminhada indiscutivelmente participam colegas, outros profissionais e certamente muitos dos aqui presentes.

O segundo ponto refere-se aos 500 anos da América, lembrando que ao longo dos tempos os humanos parecem sempre iguais, estáticos no tempo, embora tenham interferido na natureza e inventado. Algumas culturas talvez tenham evolúfdo, mas muitas foram destruídas por suas natureza/vida/sociedade.

Possamos - nós, enfermeiros - ler o que nossa realidade apresenta, participando de seu desenvolvimento, sem a aprisionar ou destruir.

Saibamos no Brasil utilizar adequadamente nossos recursos, examinar o significado e as interferencias das práticas oriundas de outras sociedades.

Possamos, nós mesmos, escrever nossas histórias com crítica, entendimento e compreensão.

Estejamos atentos aos alunos, aos clientes, à sociedade brasileira e seus descaminhos no que é nosso maior direito à vida e às condições de vida.

Não sejamos descobridores/invasores, mas tenhamos consciência que somos humanos, nesta terra constituída de tantos outros seres e espécies.

Sejamos mulheres e homens em enfermagem com nossas histórias, sem nos submetermos, revelando através da pesquisa e dela nos instrumentalizando, para garantir os direitos à saúde, à vida, à natureza.

Como educadores, priviligiemos a educação para todos, com acesso igual, numa sociedade de cidadãos livres e conscientes, não de escravos e aprisionados pela ignorância e falta de acesso a seus direitos. 